UNIVERSIDADE DE SÃO PAULO

FACULDADE DE FILOSOFIA, CIÊNCIAS E LETRAS DE RIBEIRÃO PRETO DEPARTAMENTO DE PSICOLOGIA PROGRAMA DE PÓS-GRADUAÇÃO EM PSICOLOGIA

LABORATÓRIO DE ENSINO E PESQUISA EM PSICOLOGIA DA SAÚDE

Mário Augusto Tombolato

As famílias homoparentais nas vozes de pais gays, mães lésbicas e seus/suas filhos(as) 

Mário Augusto Tombolato

\section{As famílias homoparentais nas vozes de pais gays, mães lésbicas e seus/suas filhos(as)}

\section{Versão simplificada}

(Versão original e corrigida encontram-se na unidade que aloja o Programa de Pós-Graduação)

Tese apresentada à Faculdade de Filosofia, Ciências e Letras de Ribeirão Preto da Universidade de São Paulo, como parte das exigências para obtenção do título de Doutor em Ciências, pelo Programa de Pós-Graduação em Psicologia.

Área de Concentração: Psicologia em Saúde e Desenvolvimento.

Orientador: Professor Titular Manoel Antônio dos Santos.

Ribeirão Preto - SP 
Autorizo a reprodução e divulgação total ou parcial deste trabalho, por qualquer meio convencional ou eletrônico, para fins de estudo e pesquisa, desde que citada a fonte.

\section{FICHA CATALOGRÁFICA}

Tombolato, Mário Augusto

As famílias homoparentais nas vozes de pais gays, mães lésbicas e seus/suas filho(as). Ribeirão Preto, 2019.

47 p. : il. ; $30 \mathrm{~cm}$

Versão simplificada.

Tese de Doutorado, apresentada à Faculdade de Filosofia, Ciências e Letras de Ribeirão Preto/USP. Área de concentração: Psicologia em Saúde e Desenvolvimento.

Orientador: Santos, Manoel Antônio dos.

1. Relações familiares. 2. Poder familiar. 3. Relações pais-filho.

4. Minorias sexuais e de gênero. 5. Pesquisa qualitativa. 
Tombolato, Mário Augusto

As famílias homoparentais nas vozes de pais gays, mães lésbicas e seus/suas filhos(as)

Tese apresentada à Faculdade de Filosofia, Ciências e Letras de Ribeirão Preto da Universidade de São Paulo, como parte das exigências para obtenção do título de Doutor em Ciências, pelo Programa de Pós-Graduação em Psicologia.

Área de Concentração: Psicologia em Saúde e Desenvolvimento.

Aprovado em 02 de maio de 2019.

Banca Examinadora:

Prof. Dr. Manoel Antônio dos Santos

Julgamento: aprovado

Prof. Dr. Geraldo Romanelli

Julgamento: aprovado

Profa. Dra. Rosana Machin Barbosa

Julgamento: aprovado

Profa. Dra. Daniela Auad

Julgamento: aprovado

Profa. Dra. Claudiene Santos

Julgamento: aprovado
Instituição: Universidade de São Paulo - USP

Assinatura:

Instituição: Universidade de São Paulo - USP

Assinatura:

Instituição: Universidade de São Paulo - USP

Assinatura:
Instituição: Universidade Federal de Juiz de Fora - UFJF

Assinatura:

Instituição: Universidade Federal de Sergipe - UFS

Assinatura:

Prof. Dr. Rafael de Tilio Instituição: Universidade Federal do Triângulo Mineiro - UFTM

Julgamento: aprovado Assinatura: 

Esta Tese foi desenvolvida na Faculdade de Filosofia, Ciências e Letras de Ribeirão Preto da Universidade de São Paulo, junto ao Programa de Pós-Graduação em Psicologia, Laboratório de Ensino e Pesquisa em Psicologia da Saúde (LEPPS) e Grupo de Ação e Pesquisa em Diversidade Sexual e de Gênero (VideVerso), com estágio de pesquisa ("sanduíche”) na Universidade de Cambridge (Inglaterra) no Centre for Family Research.

Recebeu apoio da Fundação de Amparo à Pesquisa do Estado de São Paulo (FAPESP), por meio da concessão de Bolsa de Doutorado (processo $n^{\circ}$ 2015/09173-0), no período de dezembro de 2015 a maio de 2019, e Bolsa Estágio de Pesquisa no Exterior (processo $\mathrm{n}^{\circ}$ 2017/08547-0), no período de setembro de 2017 a abril de 2018.

F F C L R P

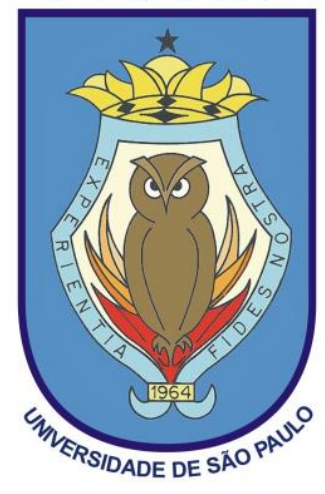

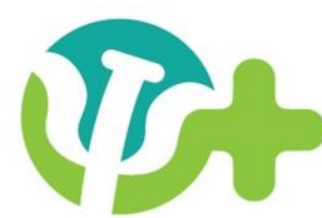

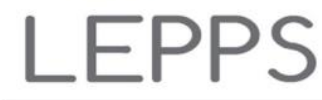

Laboratório de Ensino e Pesquisa em Psicologia da Saúde
VIDE $\mid$ O2ЯJV

grupo de ação e pesquisa em diversidade sexual e de gênero

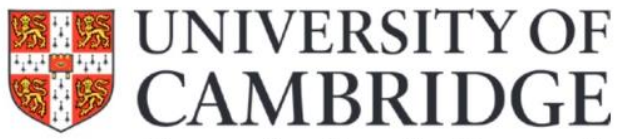

Centre for Family Research

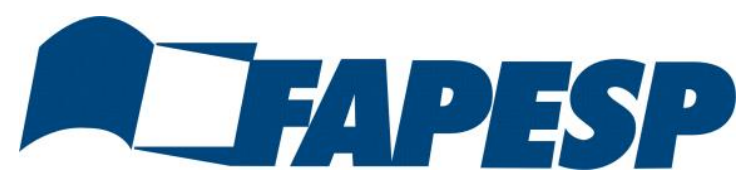





\section{AGRADECIMENTOS}

Às quatro famílias participantes desta pesquisa que gentilmente compartilharam comigo as preciosas histórias de suas vidas.

Ao meu orientador, Prof. Titular Manoel Antônio dos Santos, pela confiança, pelo companheirismo e aprendizado. A partir de nossa caminhada juntos, iniciada em 2014, desenvolvi e aprimorei meu conhecimento na Ciência Psicológica.

Aos membros da banca do Exame de Qualificação e da Defesa da Tese pelas valiosas contribuições para o aprimoramento desta pesquisa: Profa. Dra. Ana Maria Lopez Calvo de Feijoo (UERJ), Prof. Dr. Geraldo Romanelli (USP-RP), Profa. Dra. Rosana Machin Barbosa (USP-SP), Profa. Dra. Daniela Auad (UFJF), Profa. Dra. Claudiene Santos (UFS), e Prof. Dr. Rafael de Tilio (UFTM).

Aos(Às) Profs(as) Drs(as) Andréa Theodoro Toci Dias, Andreza Marques de Castro Leão, Carla Guanaes-Lorenzi, Fábio Scorsolini-Comin, Jonathan Alan Smith, Juliana Vendruscolo, Luiz Celso Castro de Toledo, Maria Helena da Nóbrega, Nichollas Martins Areco, Reinaldo Furlan, e à Profa. Ma. Edilaine Helena Scabello, pelo generoso aporte ao longo da minha trajetória e das minhas pesquisas.

Aos(Às) colegas do Laboratório de Ensino e Pesquisa em Psicologia da Saúde (LEPPS/USP), Grupo de Ação e Pesquisa em Diversidade Sexual e de Gênero (VideVerso) e, particularmente, à Andréa Carolina Benites, Carolina Leonidas e Élide Dezoti ValdanhaOrnelas, pelas seminais interlocuções.

Aos colegas da Universidade de Cambridge e do Centre for Family Research, em especial a minha supervisora Susan Golombok e a funcionária Abby Scott, cuja receptividade e atenção foram essenciais para a realização plena do meu estágio de pesquisa. (Thanks to colleagues at the University of Cambridge and the Centre for Family Research, especially my supervisor Susan Golombok and Abby Scott. Your receptivity and attention greatly contributed to the success of my research internship).

Ao Prof. Dr. Marcelo Concário pelo afetuoso apoio em grande parte desta caminhada.

Aos meus queridos familiares, especialmente meus pais Anice e Moacir, minha irmã Mariana e minha tia Marlene, pelo amor e pela segurança sempre presentes. 
Aos(Às) meus/minhas prezados(as) amigos(as) das cidades de Torrinha, Araraquara, Bauru, Ribeirão Preto e Cambridge, pela força, pelo carinho e companheirismo.

À Fundação de Amparo à Pesquisa do Estado de São Paulo (FAPESP), pelo essencial apoio financeiro para a realização desta pesquisa, por meio da Bolsa de Doutorado (processo $n^{\circ}$ 2015/09173-0) e Bolsa Estágio de Pesquisa no Exterior (processo nº 2017/08547-0).

$\mathrm{A}(\hat{\mathrm{A}})$ todos(as) que generosamente contribuíram na trajetória dos 12 anos ininterruptos de minha formação acadêmica e profissional, iniciada em 2007, com a Graduação, e concluída agora em 2019, com o Doutorado. 


\section{RESUMO}

Tombolato, M. A. (2019). As famílias homoparentais nas vozes de pais gays, mães lésbicas e seus/suas filhos(as) (Tese de Doutorado). Programa de Pós-Graduação em Psicologia, Universidade de São Paulo, Ribeirão Preto, SP.

Considerando-se a trajetória sociocultural e política da constituição da entidade familiar, assiste-se a um aumento da visibilidade dos arranjos familiares configurados por casais do mesmo sexo/gênero e seus/suas filhos(as). A aceitação social e possível regulamentação jurídica que assegure os direitos dos membros das famílias homoparentais são questões prementes na atualidade. Estudos realizados no cenário brasileiro têm evidenciado que essas famílias convivem, nos mais variados contextos relacionais, com dificuldades, enfrentando barreiras decorrentes de preconceitos e discriminação. Em face da necessidade de compreender essa realidade a partir de estudos que contemplem e deem voz aos/às integrantes das famílias homoparentais, depreende-se a relevância de conhecer como os casais formados por gays e lésbicas e seus/suas filhos(as) constituem suas vivências familiares nos âmbitos privado e social. Este estudo teve por objetivo conhecer as vivências de quatro famílias homoparentais a partir das vozes de quatro casais constituídos por dois homens e duas mulheres, e seus/suas quatro filhos(as). Os instrumentos e técnicas utilizados com os casais foram: Formulário de Dados Socioeconômicos, Critério de Classificação Econômica Brasil, Entrevista Aberta, Genograma e Mapa de Rede; com os(as) filhos(as): Formulário de Dados Socioeconômicos, Entrevista Aberta e Mapa de Rede. A Entrevista Aberta, definida como a principal técnica de coleta, foi audiogravada, transcrita na íntegra e analisada de forma articulada com os dados extraídos dos demais instrumentos aplicados, a partir do referencial teórico-metodológico da Análise Fenomenológica Interpretativa (AFI). Os resultados apontaram que os casais compartilharam suas vivências relacionadas a ser lésbica/gay em uma sociedade marcada pela homofobia, contaram as histórias detalhadas de seus relacionamentos amorosos, destacaram a relação de companheirismo como base da vivência conjugal e refletiram sobre as vivências dos papéis de gênero no relacionamento conjugal, fazendo um contraponto entre o que é esperado socialmente e o que é realmente vivenciado em suas relações cotidianas. Encontrou-se uma pluralidade de vivências conjugais e parentais, assim como de modos de acesso à parentalidade, todavia a percepção de transformação pessoal com a transição para a maternidade/paternidade e o cuidado e a preocupação relativos à educação do(a) filho(a) perpassam todas as vivências parentais. A despeito das dificuldades enfrentadas no cotidiano, das experiências de preconceito social e familiar e dos percalços da aceitação por parte das famílias de origem, todos(as) os(as) participantes afirmaram viver bem em família. Compreende-se que as vivências do ser/viver família configuram percursos singulares no processo de construção da subjetividade de cada membro da família e, particularmente, para os(as) cônjuges representam um marco fundamental rumo à apropriação de quem cada um/uma é. $\mathrm{O}$ conhecimento gerado por esta pesquisa oferece subsídios que permitem aprofundar a compreensão do fenômeno investigado, e para o planejamento de estratégias que contribuam para fornecer cuidados às famílias homoparentais e que promovam condições para que elas possam ser reconhecidas e respeitadas na sociedade brasileira. A produção e divulgação de pesquisas nesta área podem fornecer elementos para novas reflexões que contribuam para transformar posturas preconceituosas e excludentes frente ao desenvolvimento e à pluralidade das estruturas familiares existentes na contemporaneidade.

Palavras-chave: Relações familiares. Poder familiar. Relações pais-filho. Minorias sexuais e de gênero. Pesquisa qualitativa. 



\begin{abstract}
Tombolato, M. A. (2019). Same-sex/gender families in the voices of gay fathers, lesbian mothers and their children (Doctoral Thesis). Postgraduate Program in Psychology, University of São Paulo, Ribeirão Preto, SP, Brazil.

In view of the sociocultural and political constitution of the family as an institution throughout the course of history, there has been an increase in the visibility of the family arrangements made up of same-sex/gender couples and their children. Social acceptance and possible legal regulation that ensures the rights of members of same-sex/gender families are pressing issues today. Studies carried out in Brazil suggest that these families coexist in the most varied relational contexts with difficulties, facing barriers resulting from prejudice and discrimination. Given the need to understand this reality based on studies that contemplate and give voice to the members of same-sex/gender families, it is important to understand how gay and lesbian couples and their children constitute their experiences in the private and social spheres. This study explored the experiences of four same-sex/gender families from the voices of two female and two male couples, and their four children. The instruments and techniques used with the couples were The Socioeconomic Form, the Brazilian Economic Classification Criteria, the Open-ended Interview, the Genogram and the Network Map; with the children The Socioeconomic Form, the Open-ended Interview and the Network Map. The Open Interview, defined as the main collection technique, was audio-recorded, transcribed verbatim and analysed in an articulated way with the data extracted from the other instruments applied, based on the theoretical and methodological framework of the Interpretative Phenomenological Analysis (IPA). The results showed that the couples shared their experiences related to being lesbian/gay in a society marked by homophobia, told the detailed stories of their interpersonal relationships, highlighted the importance of companionship as a basis for conjugal experience and reflected on the experiences of gender roles in the marital relationship, making a counterpoint between what is expected socially and what is actually experienced in their daily lives. There was a plurality of conjugal and parental experiences, as well as ways of access to parenting, but the perception of personal transformation with the transition to motherhood/fatherhood and the care and concern regarding the education of the child permeated all parenting experiences. In spite of the difficulties faced in daily life, the experiences of social and family prejudice and the mishaps of acceptance by their families of origin, all the participants affirmed to live well with the family unit. It is understood that the experiences of living as a family constitute unique paths in the process of constructing the subjectivity of each member of the family and, in particular, for the spouses represent a fundamental landmark towards the appropriation of who each one is. The knowledge produced by this research provides support to deepen the understanding of the phenomenon investigated, and proposes subsidies for strategies that offer assistance to same-sex/gender families in order to promote conditions where they can be recognized and respected in Brazilian society. The production and dissemination of research in this area may provoke reflections that contribute to transforming prejudices and exclusionary postures in the face of the development and plurality of family forms existing in the contemporary world.
\end{abstract}

Keywords: Family relations. Parenting. Parent-child relations. Sexual and gender minorities. Qualitative research. 



\section{LISTA DE TABELAS}

Tabela 1 - Características Principais das Famílias Participantes da Pesquisa

Tabela 2 - Características do Contato e das Famílias que Não Participaram da Pesquisa 61

Tabela 3 - Duração da Aplicação dos Instrumentos e das Técnicas de Coleta de Dados 63

Tabela 4 - Características Socioeconômicas das Famílias 71

Tabela 5 - Identificando os Temas Recorrentes 160 



\section{LISTA DE FIGURAS}

Figura 1 - Modos de Acesso à Parentalidade para Indivíduos ou Casais Homossexuais 33

Figura 2 - Genograma: Tulipa e Américo 74

Figura 3 - Mapa de Rede: Américo e Tulipa 74

Figura 4 - Mapa de Rede: Torquato 94

Figura 5 - Genograma: Paulo e Bogart 103

Figura 6 - Mapa de Rede: Bogart e Paulo 103

Figura 7 - Genograma: Cláudio e Bruno 122

Figura 8 - Mapa de Rede: Bruno e Cláudio 122

Figura 9 - Genograma: Manu e Beatriz 140

Figura 10 - Mapa de Rede: Beatriz e Manu 140

Figura 11 - Mapa de Rede: Gabriela 155 



\section{SUMÁRIO}

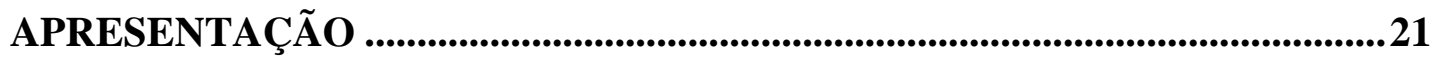

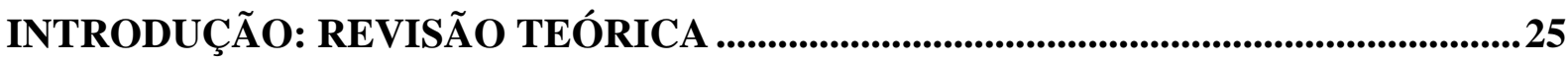

AS FAMÍLIAS OCIDENTAIS E CONTEMPORÂNEAS EM CONTÍNUA

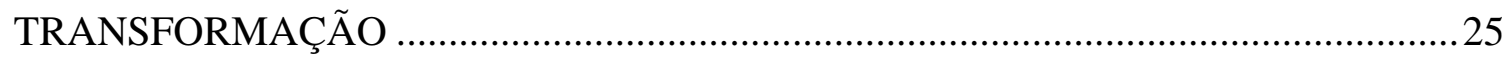

AS HOMOPARENTALIDADES: FAMÍLIAS COM PAIS GAYS/MÃES

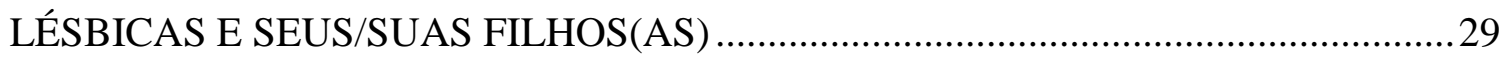

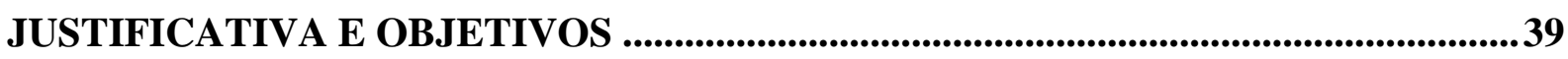

TRAJETÓRIA TEÓRICO-METODOLÓGICA ........................................................42

CONTEXTUALIZAÇÃO SOBRE A METODOLOGIA QUALITATIVA.........42

ANÁLISE FENOMENOLÓGICA INTERPRETATIVA - AFI .........................47

Algumas aplicações da AFI ............................. Erro! Indicador não definido.

PARTICIPANTES ............................................... Erro! Indicador não definido.

TÉCNICAS E INSTRUMENTOS ........................ Erro! Indicador não definido.

PROCEDIMENTO ........................................... Erro! Indicador não definido.

Considerações éticas ....................................... Erro! Indicador não definido.

Coleta de dados ................................................ Erro! Indicador não definido.

Seleção e contato com os(as) participantes ... Erro! Indicador não definido.

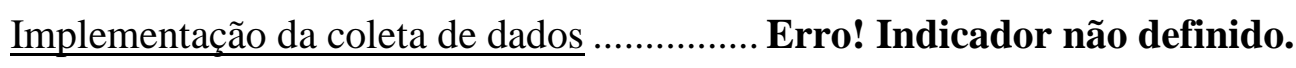

Análise dos dados

Erro! Indicador não definido.

RESULTADOS E DISCUSSÃO .................................................. Erro! Indicador não definido.

CARACTERÍSTICAS SOCIOECONÔMICAS DAS FAMÍLIAS................. Erro!

Indicador não definido.

FAMÍLIA 1: TULIPA, AMÉRICO E TORQUATO ............. Erro! Indicador não definido.

FAMÍLIA 2: PAULO, BOGART E RODRIGO ... Erro! Indicador não definido. 
FAMÍLIA 3: BRUNO, CLÁUDIO E RAFAEL ....Erro! Indicador não definido.

FAMÍLIA 4: BEATRIZ, MANU E GABRIELA ...Erro! Indicador não definido.

DISCUSSÃO

CONSIDERAÇÕES FINAIS .................................................Erro! Indicador não definido.

REFERÊNCIAS ...............................Erro! Indicador não definido.

APÊNDICES ..................................Erro! Indicador não definido.

ANEXOS ..........................................Erro! Indicador não definido. 


\section{APRESENTAÇÃO ${ }^{1}$}

A

aproximação ao tema que foi investigado nesta tese de doutorado é um desdobramento de meus interesses de pesquisa, que foi se delineando ao longo de minha trajetória acadêmica. Em 2009, durante o meu terceiro ano de graduação em Psicologia na Universidade Paulista (UNIP), campus de Araraquara, frente à necessidade da escolha de um tema de pesquisa a ser realizada dentro de duas disciplinas em Psicologia Social, meus colegas e eu consideramos a "adoção por homossexuais" a melhor opção, por se tratar de uma questão contemporânea, que apresentava incipiência de estudos, além de conciliar os interesses pessoais do grupo. Desse modo, desenvolvemos a pesquisa empírica intitulada "A representação social de estudantes universitários sobre a adoção de crianças por casais homoafetivos", orientada pelo Prof. Dr. Paulo Eduardo Benzoni, e que foi apresentada e premiada como o melhor pôster em Psicologia Social em um evento científico promovido pela universidade.

No início de 2011, meu último ano de graduação, durante uma conversa com a Profa. Ma. Edilaine Helena Scabello - orientadora do trabalho de Prática de Investigação Científica (PIC), intitulado "Resiliência em crianças e adolescentes vítimas de abuso sexual intrafamiliar: a percepção de profissionais", que foi desenvolvido por mim e mais três colegas -, relatei sobre o meu crescente interesse em pesquisar e o desejo de ingressar no curso de Mestrado, que para mim, por ser aluno de uma universidade particular, era uma realidade não tão palpável naquele momento de minha trajetória. Edilaine aproximou-me da realização desse desejo e informou-me sobre o Núcleo de Estudos da Sexualidade (NUSEX/ CNPq) e sobre o Programa de Pós-Graduação em Educação Escolar da Faculdade de Ciências e Letras da Universidade Estadual Paulista "Júlio de Mesquita Filho" (UNESP), campus de Araraquara.

A partir dessas informações preliminares, entrei em contato com o Prof. Dr. Paulo Rennes Marçal Ribeiro, que prontamente convidou-me para as reuniões do Núcleo de Estudos da Sexualidade (NUSEX), assim como para participar, como aluno convidado, na disciplina "Introdução à Sexologia e à Educação Sexual" - ofertada, por um conjunto de docentes, junto ao Programa de Pós-Graduação em Educação Escolar. Logo, concomitantemente à graduação

\footnotetext{
${ }^{1}$ Neste primeiro tópico, utilizarei a primeira pessoa do singular, uma vez que me proponho a descrever um breve panorama sobre a minha trajetória como aluno e pesquisador, de modo a também evidenciar o percurso que venho construindo no campo de investigação de famílias constituídas por casais do mesmo sexo/gênero e seus/suas filhos(as).
} 
em Psicologia, eu participava das reuniões do grupo de estudos do NUSEX, coordenado pela estimada Profa. Dra. Andreza Marques de Castro Leão, e da referida disciplina.

No início de 2012, ingressei no curso de Mestrado do Programa de Pós-Graduação em Psicologia do Desenvolvimento e Aprendizagem da Faculdade de Ciências, da Universidade Estadual Paulista "Júlio de Mesquita Filho" (UNESP), campus de Bauru. Simultaneamente ao curso de Mestrado, no ano de 2013, iniciei o curso de Especialização em Psicologia Clínica e Hospitalar oferecido pelo Hospital de Reabilitação em Anomalias Craniofaciais (HRAC) da Universidade de São Paulo - USP, campus de Bauru, popularmente conhecido como “Centrinho". Em agosto de 2014 concluí o curso de Especialização apresentando a monografia "Depressão pós-parto em mães de bebês com fissuras labiopalatinas", orientada pela Profa. Dra. Olga Maria Piazentim Rolim Rodrigues, e defendi minha dissertação de Mestrado intitulada "Desvelando a família homoparental: um estudo sobre os relatos de casais homossexuais com filhos", sob orientação da Profa. Dra. Ana Cláudia Bortolozzi Maia, e com apoio da Fundação de Amparo à Pesquisa do Estado de São Paulo (FAPESP).

Entrelaçando os meus interesses pessoais aos meus primeiros passos como pesquisador, e à realidade atual de maior visibilidade das homossexualidades e das homoparentalidades nos âmbitos científico e social, emergiu em mim a necessidade de prosseguir com meu percurso de construção de conhecimento na temática. Consequentemente, motivado por esse contexto, decidi por investigar, de forma empírica, a vivência familiar de casais do mesmo sexo e seus/suas filhos(as), e com esse propósito ingressei, no início de 2015, no curso de Doutorado do Programa de Pós-Graduação em Psicologia, da Faculdade de Filosofia, Ciências e Letras de Ribeirão Preto da Universidade de São Paulo (FFCLRP-USP), sob orientação do Prof. Titular Manoel Antônio dos Santos. Novamente obtive o apoio da Fundação de Amparo à Pesquisa do Estado de São Paulo (FAPESP).

Durante esse período de quatro anos do curso do Doutorado, me dediquei às diversas etapas e atividades para a construção desta tese, com destaque ao complexo processo de coleta de dados. Além de cursar disciplinas do Programa de Pós-Graduação no qual estou matriculado, cursei outras em mais dois Programas de Pós-Graduação. Dentre as diversas atividades realizadas, destaco: fui representante discente junto à Comissão Coordenadora do Programa de Pós-Graduação, participei do Programa de Aperfeiçoamento de Ensino (PAE), das reuniões semanais do Laboratório de Ensino e Pesquisa em Psicologia da Saúde (LEPPS) e do Grupo de Ação e Pesquisa em Diversidade Sexual e de Gênero (VideVerso), apresentei estudos em eventos científicos nacionais e internacionais, elaborei manuscritos e publiquei 
dois artigos científicos em periódicos avaliados como Qualis CAPES A1 em Psicologia. Nesse ínterim, após a aprovação no Exame de Qualificação da Tese, realizei o estágio de pesquisa no exterior, por seis meses, no Centre for Family Research (CFR), da Universidade de Cambridge, Reino Unido, com apoio da FAPESP. Desenvolvi o projeto intitulado "Families with same-sex couples and their children: broadening research perspectives", sob supervisão da Profa. Dra. Susan Golombok. Além disso, participei de uma reunião acadêmica com o professor Jonathan Smith e de um workshop com o professor Paul Flowers, que são os principais autores do referencial teórico-metodológico adotado neste estudo, a saber, Análise Fenomenológica Interpretativa (AFI). A rica e intensa lista das atividades realizadas no Reino Unido criou um cenário favorável para o aprimoramento desta tese, além de contribuir para minha formação enquanto pesquisador.

Por fim, apresento a tese de doutorado que está organizada da seguinte forma: (1) a introdução abarcando uma revisão e discussão teórica em torno de determinados aspectos dos temas famílias e homoparentalidades; (2) a justificativa e os objetivos; (3) a trajetória teóricometodológica; (4) os resultados e a discussão dos dados; (5) as considerações finais; (6) as referências; e (7) os apêndices e anexos. 


\section{INTRODUÇÃO: REVISÃO TEÓRICA}

\section{AS FAMÍLIAS OCIDENTAIS E CONTEMPORÂNEAS EM CONTÍNUA TRANSFORMAÇÃO}

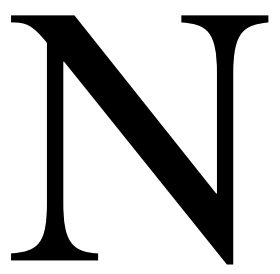

este primeiro capítulo, pretende-se assinalar determinados aspectos que julga-se essenciais para a compreensão do panorama da instituição familiar no decorrer dos tempos. Entretanto, o escopo deste texto não é apresentar uma revisão detalhada e circunstanciada sobre o tema, em relação ao qual já existe uma extensa e consolidada literatura, principalmente nas áreas das Ciências Humanas e Sociais. Assim, há referências a determinados cenários que considera-se cruciais para situar o problema de pesquisa que dá fundamentação e inteligibilidade à esta investigação.

Na sociedade contemporânea e ocidental a família é considerada a mais comum das instituições na qual convivem os indivíduos, sendo o núcleo organizador a partir do qual se estruturam e transmitem os valores mais importantes da nossa cultura (Oliveira, 2011; Romanelli, 1998; Singly, 2007). A família não é considerada uma entidade fixa, e sim um ambiente em constante variação no qual se desenvolvem as normas de conjugalidade, filiação e parentesco, construindo sistemas elementares cuja finalidade é ligar os indivíduos entre si e à sociedade (Lévi-Strauss, 1949/1982). A essa definição conceitual, Badinter (1985, p. 26) acrescenta que:

é em função das necessidades e dos valores dominantes de uma dada sociedade que se determinam os papéis respectivos do pai, da mãe e do filho. Quando o farol ideológico ilumina apenas o homem-pai e lhe dá todos os poderes, a mãe passa à sombra e sua condição se assemelha à da criança. Inversamente, quando a sociedade se interessa pela criança, por sua sobrevivência e educação, o foco é apontado para a mãe, que se torna a personagem essencial, em detrimento do pai. Em um ou outro caso, seu comportamento se modifica em relação ao filho e ao esposo.

Segundo Ariès (1986), a concepção que temos hoje de família desenvolveu-se na Europa em meados do século XVIII. O casamento, anteriormente pautado como um arranjo de duas famílias visando à garantia de transmissão do patrimônio e/ou dos laços de linhagem, transformou-se em um vínculo com o propósito de conciliar interesses afetivos e sociais, fundamentando-se a partir de então no amor, no sentimento de felicidade e na liberdade

${ }^{2}$ As referências utilizadas nesta tese provêm de variadas fontes: frequentes consultas em bases de dados, sugestões de pesquisadores nacionais e internacionais da área, cursos, livros, entre outras. Englobam a experiência do pesquisador na temática desde 2009. 
individual. A procriação era considerada ponto culminante do casamento e, aos pais, cabia não somente a reprodução biológica, mas especialmente a educação e os cuidados com os filhos, envolvendo transmissão de valores, costumes e tradições sociais (Badinter, 1985).

Nesse sentido, a família passa a ter por objetivo central a socialização das crianças de maneira afetuosa, tendo como prioridade a privacidade da relação do casal e dos(as) filhos(as). Isso significa que a concepção sobre o papel, função e atuação da família modificou-se substancialmente, sendo elaborados os sentimentos de paternidade e maternidade (Ariès, 1986). “A 'dedicação' que é possível ser despendida ao filho(a) aparece como a medida da legitimidade da parentalidade, fazendo com que a dimensão afetiva seja valorizada como o aspecto mais importante na constituição de vínculos familiares" (Tarnovski, 2002, p. 50).

De acordo com Peixoto (2007), em meados da década de 1950 o modelo estimado de família era aquele estabelecido pelo casal de homem e mulher, unidos por casamento legal, e seus/suas filhos(as). Nesse âmbito, principalmente no contexto das camadas médias e altas da sociedade, o pai era o provedor do lar, e a mãe era a dona de casa, e a principal responsável pela criação e educação dos(as) filhos(as). Segundo a mesma autora, a partir dos anos 1960 a família contemporânea ocidental passou por grandes transformações. O referido modelo "perde vigor e declina à medida que as mulheres se inserem no mercado de trabalho, tendo de conciliar a atividade profissional com a responsabilidade familiar" (p. 11). Além desses fatores, "o controle da fecundidade por meio da contracepção e o aumento do número de divórcios, de uniões livres e de recomposições familiares, também contribuíram para o surgimento de outras formas de vida familiar" (Peixoto, 2007, pp. 11-12).

À sombra dessas reflexões, atualmente em nossa sociedade podemos considerar que o farol ideológico que norteia a constituição familiar está baseado, principalmente, nos vínculos de afinidades e afetos entre os membros, como apontam Pozzetti e Silva (2013, p. 110):

o conceito de família independe da forma como foi constituída, quer seja oriunda do casamento, da união estável, monoparental, com ou sem filhos biológicos ou adotivos, bastando que para tanto haja afinidade entre as pessoas que a constituam e que estas se considerem parentes, ainda que por vínculos unicamente de afeto.

É amplamente reconhecido que a instituição familiar é perpassada por inúmeras transformações ao longo do tempo e, por essa razão, não se deve apenas considerar a existência de um único tipo de organização de familiar. Pelo contrário, as alterações ocorridas na configuração da estrutura e funcionamento familiar ao longo da história vêm, continuamente, expandindo o significado de família. Os diversos arranjos familiares não 
devem ser entendidos, necessariamente, como decorrentes de uma crise da instituição familiar, mas como reflexos das recorrentes mudanças que impulsionam a sociedade e modificam as concepções dos valores dominantes e do modo como se vive e entende a convivência familiar (Araújo, Oliveira, Sousa, \& Castanha, 2007; Roudinesco, 2003). Nessa lógica, o "pluralismo familiar", que caracteriza o contemporâneo, pode ser compreendido como "o resultado de uma transformação profunda das relações de gênero ${ }^{3}$ e da emergência de um novo equilíbrio entre autonomia individual e pertencimento familiar" (Peixoto, 2007, p. 12).

A despeito dessas considerações, o modelo familiar legitimado e socialmente almejado é ainda restrito ao enquadre nuclear-monogâmico, organizado a partir da união de um casal formado por um homem e uma mulher heterossexuais (Rodriguez \& Paiva, 2009). Essa ideologia de modelo familiar norteia, por exemplo, as práticas sociais e educacionais e atua, na maioria das vezes, segregando as outras organizações que divergem desse ideal arraigado no imaginário social.

Do ponto de vista jurídico, a Comissão Especial do Estatuto da Família referente ao Projeto de Lei No 6.583 de 2013 (Câmara dos Deputados, 2013) aprovou recentemente, em 2015, essa construção ideológica ao definir a "entidade familiar como o núcleo social formado a partir da união entre um homem e uma mulher, por meio de casamento ou união estável, ou ainda por comunidade formada por qualquer dos pais e seus descendentes" (Artigo $2^{\circ}$, p. 1). Atualmente, em vias de tramitação, o Projeto de Lei está aguardando deliberação do recurso na Mesa Diretora da Câmara dos Deputados e posteriormente deve avançar para a análise do Senado Federal. Outros diplomas legais, como a Constituição Brasileira de 1988 (Constituição da República Federativa do Brasil de 1988, 2016), referendam essa concepção de família: "para efeito da proteção do Estado, é reconhecida a união estável entre o homem e a mulher como entidade familiar, devendo a lei facilitar sua conversão em casamento" e "entende-se, também, como entidade familiar a comunidade formada por qualquer dos pais e seus descendentes" (Capítulo VII, Artigo 226, $3^{\circ}$ e $4^{\circ}$ ). Como se verá posteriormente, tal concepção pode entrar em conflito com a resolução de maio de 2011 do Supremo Tribunal

\footnotetext{
${ }^{3}$ Basicamente, considera-se gênero como "classificação pessoal e social das pessoas como homens ou mulheres. Orienta papéis e expressões de gênero. Independe do sexo" (Jesus, 2012, p. 24) e expressão de gênero como "forma como a pessoa se apresenta, sua aparência e seu comportamento, de acordo com expectativas sociais de aparência e comportamento de um determinado gênero. Depende da cultura em que a pessoa vive" (p. 24).
} 
Federal (STF) brasileiro, que legitima juridicamente como entidade familiar as uniões entre pessoas do mesmo sexo ${ }^{4}$.

Pode-se compreender a definição de família a partir de várias concepções teóricas. No entanto, como ressaltado anteriormente, tais concepções sempre estarão sujeitas a certa instabilidade e imprecisão conceitual por estarem em constante transformação. Destarte, a família não é algo naturalmente dado, e sim determinada por aspectos socioculturais, políticos e econômicos de uma época, que impõem variações na sua dinâmica e estrutura. É no marco dos modelos alternativos de arranjos familiares que se situam as famílias constituídas por casais do mesmo sexo/gênero e seus/suas filhos(as), também denominadas de famílias homoparentais ou, em determinados casos na linguagem jurídica brasileira, homoafetivas (Farias \& Maia, 2009; Oliveira, 2011).

\footnotetext{
${ }^{4}$ Sexo, nesta tese, é entendido como a "classificação biológica das pessoas como machos ou fêmeas, baseada em características orgânicas como cromossomos, níveis hormonais, órgãos reprodutivos e genitais. Ao contrário da crença popular, reiterada em diferentes discursos, a categoria sexo não se configura como uma dualidade simples e fixa entre indivíduos deste e daquele sexo (binarismo ou dimorfismo sexual), mas, isso sim, como um contínuo complexo de características sexuais" (Jesus, 2012, p. 24).
} 


\section{AS HOMOPARENTALIDADES: FAMÍLIAS COM PAIS GAYS/MÃES LÉSBICAS E SEUS/SUAS FILHOS(AS)}

Antes da continuação do desenvolvimento do tema, é preciso contextualizar acerca das relações afetivo-sexuais estabelecidas entre pessoas do mesmo sexo/gênero - o que denomina-se hoje, de modo geral, como homossexualidades - que se configuraram de distintos e específicos modos e estão presentes na sociedade no decorrer de toda a história da humanidade (Uziel, 2007; Zambrano, 2006). De acordo com Vieira (2011), a homossexualidade é compreendida como uma das variantes das relações afetivo-sexuais dentro do panorama da sexualidade humana. A concepção que se tem atualmente de homossexualidade constituiu-se a partir de um processo de identidade, lutas e conquistas travadas no decorrer do tempo, porém, "ainda se enfrentam discursos opositores do campo moral e, principalmente, religioso, o que impede o avanço na conquista de direitos dos sujeitos que se reconhecem e se identificam como homossexuais" (Vieira, 2011, p. 16).

Concomitantemente a esse processo histórico, cultural e político — que atua como pano de fundo para as transformações em curso das relações entre pessoas do mesmo sexo/gênero - , vê-se entrelaçada outra temática relevante a esse contexto que diz respeito às relações familiares e parentais, exercidas por pessoas que se reconhecem homossexuais e/ou que vivem uma parceria afetiva com pessoa do mesmo sexo. A "homoparentalidade" é um neologismo proveniente da França, criado em 1996/1997 pela Associação de Pais e Futuros Pais Gays e Lésbicas - APGL (Roudinesco, 2003). Tal conceito nomeia a singularidade com que pessoas lésbicas/gays exercem a parentalidade, ou seja, a situação na qual pelo menos um adulto que se autodesigna homossexual é, ou pretende ser, pai ou mãe de, no mínimo, uma criança (Zambrano, 2006).

A homoparentalidade, como denominação recentemente dada a um determinado formato de família, deve ser compreendida levando-se em consideração um contexto sociocultural de lutas e conquistas de direitos para o seu reconhecimento e respeito (Rodriguez, 2012). Por outro lado, Singly (2007) ressalta que ao se definir as famílias pela perspectiva de sua forma ou estrutura, a partir dos membros que a constituem, há o risco de não se evidenciar o caráter das relações intrafamiliares, que são os elementos fundamentais de análise no plano teórico. Portanto, é preciso ter cautela na utilização do termo homoparentalidade, muito embora se perceba, na atualidade, uma certa tendência dos estudos científicos de abonarem sua aplicação. Nesse sentido, segundo o referido autor, alegar que a família nuclear "sempre existiu não significa, entretanto, dizer que esta família sempre 
preenche funções idênticas, ou que a regulação das relações entre os sexos e as gerações seja a mesma" (Singly, 2007, p. 31). Por exemplo, as famílias nucleares brasileiras dos anos 1970 apresentam aspectos diferentes se comparadas às famílias nucleares dos dias de hoje. É imprescindível, então, relativizar nossas concepções teóricas, vendo-as em perspectiva, segundo o contexto histórico em que nossa análise incide.

Nesse sentido, Toledo (2008) assinala que nomear a família de pais e mães do mesmo sexo/gênero com o termo "homoparental" circunscreve, no momento atual, a afirmação da diversidade e da visibilidade no esforço por ampliar conquistas e fortalecer o espírito dos movimentos de liberação sexual que remontam à década de 1960. Entretanto, principalmente nos países de língua inglesa, o termo homoparentalidade não é referendado, havendo preferência pelas expressões mais consagradas como same-sex couples, same-gender couples, gay and lesbian families ou gay and lesbian parenthood. Tais expressões decorrem do fato de evitarem a utilização de qualquer denominação psiquiátrica ou similares, preferindo endossar termos centrados no gênero (Toledo, 2008; Vieira, 2011). Embora haja uma ampla discussão com perspectivas favoráveis ou não sobre o emprego do termo homoparental, nesta tese, optou-se pelo seu uso. Em relação à parentalidade homossexual, Uziel (2007, p. 78) considera que a:

homossexualidade refere-se ao exercício da sexualidade. Funções parentais não exigem o exercício da sexualidade. Seria o mesmo que usar este critério para julgar a competência profissional de alguém, sua capacidade para gerenciar conflitos, seu gosto por comida, gênero de filme. São esferas distintas da vida, que se cruzam por uma contingência. A reprodução, muito atrelada à sexualidade, pode ser um dos fatores que dêem sentido à proximidade dessas duas esferas, bem como a conjugalidade, a afetividade. São aspectos comuns, como poderíamos encontrar se buscássemos qualquer outra relação (p. 78).

Em consonância com essa linha argumentativa, entende-se que as famílias homoparentais possivelmente não instituem nada de novo no que tange à parentalidade. Ou seja, independentemente de a definição da configuração familiar ser monoparental, biparental, pluriparental, heteroparental ou homoparental, a esfera da função da parentalidade relacionase ao exercício de direitos e de deveres quanto aos cuidados com os(as) filhos(as). Logo, não tem a ver diretamente com a sexualidade/ orientação sexual dos pais e das mães. Nesse sentido, são reconhecidas as diversas referências a estudos científicos que colocam o foco no bem-estar familiar e na aparentemente comprovada não influência da orientação homossexual dos pais na definição da orientação sexual dos(as) filhos(as) (Gato, 2014; Golombok, 2015; Golombok et al. 2003; Teixeira Filho, Toledo, \& Godinho, 2007). 
Segundo Lauriano e Duarte (2011), os dados divulgados pelo Instituto Brasileiro de Geografia e Estatística (IBGE), o Censo de 2010 revelou que existem no Brasil mais de 60.000 casais homossexuais. Foi a primeira vez que o governo brasileiro instaurou e demonstrou a preocupação com a visibilidade e proceder à quantificação do número desses casais no país. Sabe-se que "a materialização das uniões homoafetivas já ocorre há muito no Brasil. Entretanto, a falta de formalização desta união é que não permitia às pessoas nesta condição gozar da segurança jurídica a que todo cidadão brasileiro tem direito" (Pozzetti \& Silva, 2013, p. 108).

Em maio de 2011, o Supremo Tribunal Federal (STF) brasileiro declarou o reconhecimento da união estável para casais do mesmo sexo, desse modo legitimando-os juridicamente como entidade familiar. Dois anos após esse acontecimento, em maio de 2013, durante a $169^{a}$ Sessão Plenária do Conselho Nacional de Justiça (CNJ) foi aprovada a resolução que habilita a celebração de casamento civil, ou de conversão de união estável em casamento para casais do mesmo sexo (Supremo Tribunal Federal, 2013). Sendo assim, essa contemporânea interpretação da atual legislação da Constituição Brasileira permite aos casais do mesmo sexo a possibilidade de casamento civil, resguardando os seus direitos humanos, civis, sociais e políticos. Tais fatos consolidam um marco na conquista de direitos por lésbicas, gays, bissexuais, travestis e transexuais (LGBT). No cotidiano dessas famílias, significa um amparo legal que pode contribuir tanto para mudanças no olhar sobre essas configurações, quanto para coibir o preconceito, a discriminação e a violência (Grossi, Uziel, \& Mello, 2007). A legislação nacional, nesse aspecto, foi ao encontro da necessidade de adaptação às mudanças ocorridas na vida da sociedade, considerando a dimensão dinâmica e complexa das relações sociais e familiares.

Verifica-se, na prática, um contingente significativo de uniões conjugais estabelecidas por pares do mesmo sexo, todavia, no que concerne ao direito à adoção de crianças por essas pessoas, a legislação brasileira não possui uma norma jurídica que permita ou impeça, de forma explícita, essa prática (Almeida, 2012; Haag, 2007; Oliveira, 2011; Pozzetti \& Silva, 2013). Embora se reconheçam determinados casos em que a adoção de crianças foi concedida para ambos os membros do casal, mais por iniciativa dos juízes do que pelo apoio inequívoco do princípio legal, "no Brasil, é mais comum encontrar famílias homoparentais com filhos que são fruto de relacionamentos heterossexuais anteriores" (Rodriguez, 2012, p. 17).

Segundo a Secretaria Especial de Comunicação Social (Senado Federal, 2013), o processo de adoção no Brasil envolve determinadas etapas e exigências. O interessado em adotar deve ser maior de 18 anos. É necessário o cadastro com informações e documentos 
pessoais, antecedentes criminais e judiciais na Vara da Infância e Juventude. Posteriormente, o juiz analisa o pedido a partir dos pré-requisitos legais. Os candidatos habilitados são convocados para entrevistas e, se aprovados, passam a integrar o cadastro nacional, que segue a ordem cronológica de classificação. Quando a criança ou adolescente está apto à adoção, o adotante inscrito no cadastro é convocado. O prazo médio para o processo de adoção é de um ano, porém, se o processo contiver algum conflito, pode se estender por anos.

Os estudos sobre adoção de crianças na realidade brasileira pouco contemplam as particularidades dos casais do mesmo sexo e da diversidade sexual (Farias \& Maia, 2009; C. Fonseca, 2002). A literatura acerca da adoção por indivíduos ou casais homossexuais ainda é incipiente (Amazonas, Veríssimo, \& Lourenço, 2013; Rosa, Melo, Boris, \& Santos, 2016, Tombolato, Maia, \& Santos, 2019). Nesse tema, há escassas investigações que focalizam a experiência da maternidade em mães adotivas heterossexuais (Sonego \& Lopes, 2009). Além disso, no contexto da maternidade lésbica, os limitados estudos existentes abordam a parentalidade biológica (Corrêa, 2012; Martinez, 2011; D. A. Silva, 2013). Por conseguinte, há parcas pesquisas que enfocam a temática de mães adotivas lésbicas.

Em suma, considerando as diferentes possibilidades para os homossexuais terem acesso à parentalidade, Zambrano (2006) destaca as quatro formas principais. A primeira delas é a recomposição: um membro do casal traz para a sua relação homossexual o(a) filho(a) de uma ligação heterossexual anterior. A segunda maneira é a adoção, podendo ser realizada pelo casal ou por um dos membros, e ser legal ou informal. Uma terceira possibilidade é o uso das técnicas de reprodução humana, visando o nascimento de filhos(as) biológicos(as). Dentro dessa possibilidade, o método mais utilizado pelas lésbicas é a Inseminação Artificial ou a Fertilização In Vitro. Os gays que desejam ter filhos(as) biológicos(as), nesse caso, podem fazer uso da Doação Temporária de Útero (popularmente conhecida por "barriga de aluguel" ou "barriga solidária"), que se trata de um procedimento, no Brasil, de caráter voluntário e sem vínculo comercial entre as partes envolvidas. Por último, a quarta alternativa é denominada coparentalidade, na qual os cuidados à criança, que passa a fazer parte da vida do casal, são exercidos de forma conjunta e igualitária pelos(as) parceiros(as), podendo aparecer entrelaçada com as formas de acesso citadas anteriormente (recomposição familiar, adoção, e reprodução humana assistida). Por exemplo:

o planejamento conjunto pode, também, incluir dois casais homossexuais, um masculino e o outro feminino, que decidem ter um filho através de inseminação artificial caseira (coleta de sêmen do pai e introdução do esperma na vagina da mãe, com o auxílio de uma seringa, sem a presença do médico) ou medicamente assistida (feita em clínica médica especializada). Nesse 
caso, a criança terá dois pais e duas mães, sendo dois deles pai e mãe biológicos (Zambrano, 2006, p. 133).

A partir da perspectiva do casal, em todas as maneiras referidas de dar concretude ao projeto de parentalidade por pessoas que se auto definem como homossexuais, há sempre um terceiro mediando o desejo de conceber um filho; em última análise, o casal depende de "um outro" para tornar possível o projeto parental (Passos, 2005).

Adiante, na Figura 1, estão esquematizados os modos de acesso à parentalidade para indivíduos ou casais homossexuais, ilustrados a partir dos(as) filhos(as) por meio da via biológica ou social.

Figura 1 - Modos de Acesso à Parentalidade para Indivíduos ou Casais Homossexuais

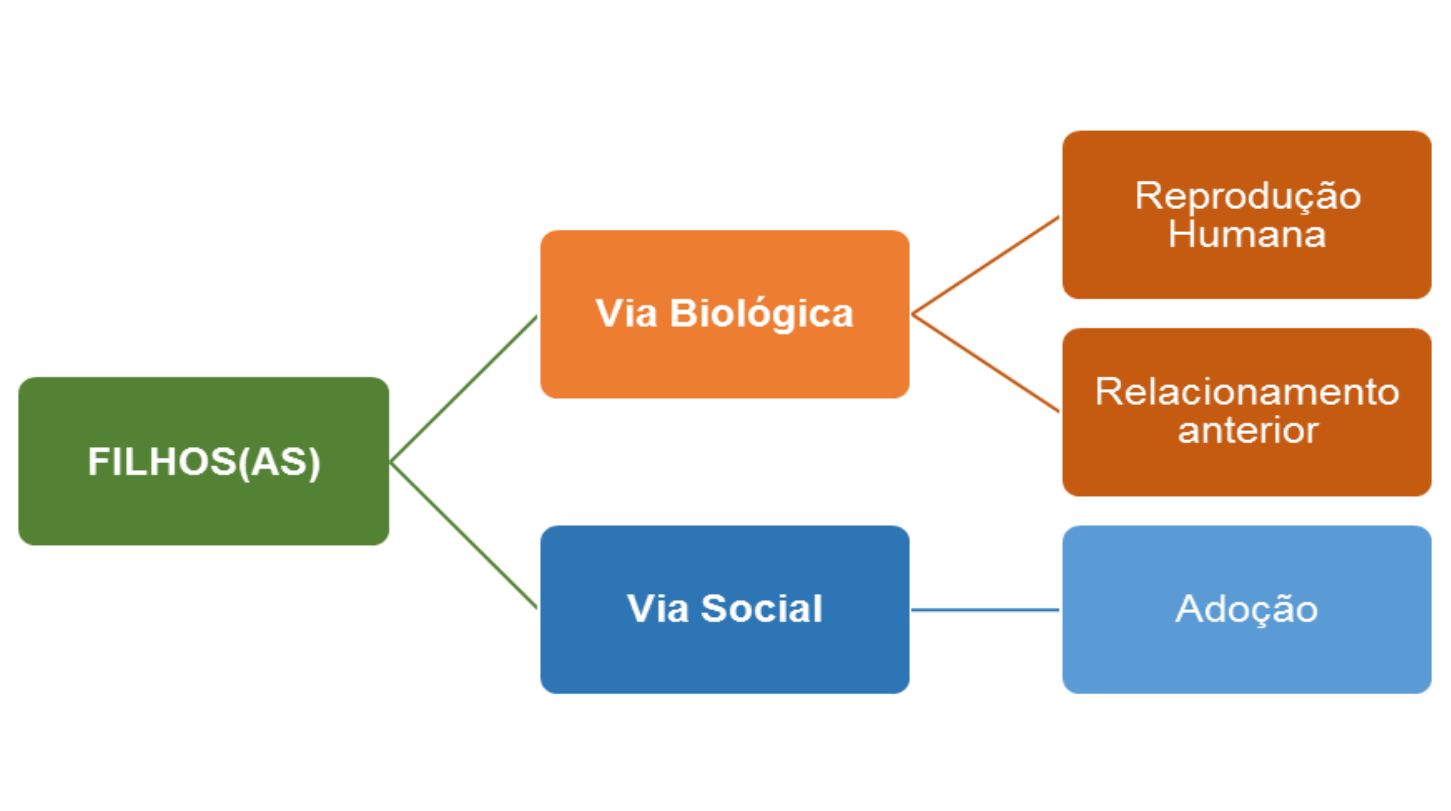

Fonte: Elaboração do autor.

Passos (2005) afirma que as novas formas de "ser família" devem ser compreendidas segundo o enfoque de uma ética que considere as demandas afetivas dos sujeitos nelas envolvidos. Nesse sentido, a ética deve estar assentada nas diferentes formas de conjugalidade, parentalidade e filiação que constroem um contexto familiar fundamentado em laços de afeto. Tais princípios éticos adviriam não mais das leis gerais que constituíam a ordem familiar patriarcal, mas das novas redes que abarcam as relações de afeto nas novas famílias. Logo, "se o parentesco é uma ordem simbólica, pode ser ressignificado. Família tem a ver com grupo de pertencimento, sendo um conceito móvel e polissêmico" (Oliveira, 2011, p. 356). Nesse contexto, estabelecem Pozzetti e Silva (2013, p. 112): 
qualquer que seja a forma de constituição de entidade familiar - quer seja através do casamento civil, religioso, união estável, família monoparental ou união homoafetiva - cabe ao Estado proteger a cada um de seus membros, assegurando-lhes a fruição de igualdade de direitos e deveres, em virtude do compromisso constitucional de garantir isonomia no tratamento de todos os cidadãos brasileiros.

Quando se aborda a questão sobre o desejo de ter filhos, os casais formados por pessoas homossexuais se diferenciam dos casais constituídos por pessoas de sexos opostos unicamente por serem duas pessoas do mesmo sexo. Entretanto, faz-se necessário analisar cada situação para compreender as realidades vivenciadas por cada casal (Gratton, 2008). Sabe-se, por outro lado, que a função de cuidar está mais relacionada à personalidade e às características do indivíduo do que ao seu sexo ou gênero (Badinter, 1985; C. Santos, 2004; Vieira, 2011).

Dentro do contexto das famílias compostas por casais do mesmo sexo/gênero e seus/ suas filhos(as), é essencial considerar as demandas da criança em relação à família: que premissas relacionais dentro do espaço familiar são fundamentais para a estruturação psíquica da criança, quais delas seriam estruturantes dos laços afetivos em qualquer tipo de família, como cuidar, acolher, conter, reconhecer e inserir a criança em uma cadeia de transmissão geracional (Passos, 2005). "Seja num casal de homens ou num casal de mulheres, as duas funções parentais podem ou não estar presentes e operantes, assim como em qualquer outro casal de homem e mulher" (Vieira, 2011, p. 193).

Nesse sentido, para a entidade familiar, o importante é a organização psíquica dos que cuidam da criança, isto é, o fundamental para o desenvolvimento do indivíduo é a possibilidade de ele manter relações saudáveis com seus responsáveis e irmãos, e permitir o desenvolvimento de todos os indivíduos que formam a família (Uziel, 2007).

No cenário de Amsterdã (Holanda), Bos, Balen e Boom (2003) realizaram um estudo no qual analisaram as motivações para o desejo de ter filhos relatadas por 100 casais heterossexuais sem problemas de fertilidade, e por 100 casais de mulheres lésbicas que tiveram filhos biológicos por meio de técnicas reprodutivas. Constataram que os motivos apresentados por ambos os grupos são bastante similares, apontando os seguintes fatores como motivadores do desejo de ter filhos: a expectativa da felicidade em estar com a criança; expectativa quanto ao bem-estar trazido para a relação do casal, tornando-o "completo"; a própria expectativa sobre parentalidade/ maternidade e de poder vivenciar a gravidez e o nascimento do bebê; a expectativa da continuidade trazida pela criança, como uma forma de os membros do casal continuarem vivos mesmo após sua morte; o fortalecimento da 
identidade como um aspecto necessário para a vida adulta; e, por último, o controle social, que se refere à pressão social para que o casal tenha filhos e transmita seus valores à sua descendência.

Alguns estudos, de abordagem qualitativa, que contemplam a temática das famílias homoparentais brasileiras evidenciaram peculiaridades no contexto desse arranjo familiar. Nessas pesquisas são discutidas diversas questões, entre elas:

- o assumir da homossexualidade diante dos percalços da aceitação e rejeição na vivenciados na esfera familiar (C. Santos, 2004; D. A. Silva, 2013; Toledo, 2008; Tombolato, 2014);

- a brevidade na decisão em morar com seus/suas parceiros(as) (Toledo, 2008; Tombolato, 2014);

- as motivações para a parentalidade (Almeida, 2012; C. Santos, 2004; Vieira, 2011);

- os modos mais habituais que as pessoas homossexuais encontram para terem acesso à parentalidade (Almeida, 2012; Corrêa, 2012; Hernández, 2013; Rodriguez \& Paiva, 2009; Rosa et al., 2016; C. Santos, 2004; D. A. Silva, 2013; Tarnovski, 2002; Uziel, 2007; Vieira, 2011);

- as experiências dos casais diante da adoção de seus/suas filhos(as) e da reprodução humana assistida (Almeida, 2012; Corrêa, 2012; Martinez, 2011; Moschetta, 2011; D. A. Silva, 2013; Tombolato et al., 2019);

- a discriminação que incide sobre as famílias homoparentais em suas relações com parentes próximos, amigos, trabalho, escola, Igreja, entre outros (Almeida, 2012; Corrêa, 2012; Farias \& Maia, 2009; Grossi et al., 2007; Hernández, 2013; Lira, Morais, \& Boris, 2016; Moscheta, 2004; Natividade \& Oliveira, 2013; Rodriguez, 2012; Rodriguez \& Paiva, 2009; C. Santos, 2004; D. A. Silva, 2013; Tarnovski, 2002; Toledo, 2008; Tombolato, 2014; Tombolato, Maia, Uziel, \& Santos, 2018; Uziel, 2007; Vieira, 2011).

Vê-se que a rede de apoio social tem aparecido nos estudos como fator proeminente, que interfere na qualidade da vivência da família homoparental. Dentre essas pesquisas, Toledo (2008) investigou o discurso sobre família a partir dos relatos de dez homens membros de famílias homoparentais. Os principais resultados demonstraram que os enunciados dos participantes acerca de suas famílias de origem foram marcados por rejeição, perdas e sofrimento. Além disso, eles defenderam a normalidade de si mesmos, de suas famílias e seus filhos. Almeida (2012), em outro momento, realizou uma pesquisa com uma família homoparental na qual um casal de homens adotou dois meninos. Os resultados 
apontaram que, apesar do fator singular da homoparentalidade, a família dos participantes retoma os valores do modelo tradicional familiar.

Tombolato (2014) pesquisou a vivência familiar a partir dos relatos de cinco casais homossexuais com filhos(as). Nesse estudo de abordagem qualitativa, o autor utilizou para a coleta de dados dois instrumentos: "Questionário de Perfil Socioeconômico de Famílias Homoparentais Brasileiras", e uma entrevista semiestruturada "Conhecendo as Famílias Homoparentais Brasileiras". As entrevistas foram audiogravadas, transcritas na íntegra, e submetidas à análise de conteúdo. As categorias e subcategorias identificadas e analisadas foram: (1) As motivações para a parentalidade: convivência com crianças familiares; motivações subjetivas e sociais; e divergências entre o casal; (2) Os procedimentos de acesso à parentalidade: adoção; reprodução humana assistida; e filha de um relacionamento heterossexual anterior; (3) A rotina familiar e a criação dos filhos: a vida dos casais após a chegada dos filhos; a rotina familiar nos cuidados dos filhos; as características das funções parentais; os cuidados na criação dos filhos; e a aceitação e os modos como os filhos chamam pelos pais e mães; (4) As relações da família homoparental com sua família de origem: modificações nas relações familiares após a chegada das filhas dos casais; suporte familiar: a contribuição dos familiares e avós nos cuidados com as crianças; pouco ou sem contato com os familiares de origem; (5) As famílias homoparentais e a sociedade: preconceito, discriminação e reconhecimento de direitos; vigia social; redes de apoio social; e facilidades e dificuldades da família homoparental.

Os resultados da análise do referido estudo demonstraram uma recorrência de características: quanto à homossexualidade no âmbito dos familiares de origem, às motivações e vivências de acesso à parentalidade dos casais homossexuais, à rotina familiar e ao cuidado com os filhos, à relação das famílias homoparentais com seus familiares e a sociedade. Portanto, a pesquisa considerou que a família homoparental apresenta características e funções que são comuns a qualquer tipo de configuração familiar (cuidado, responsabilidades e dificuldades na criação dos filhos; planejamento financeiro e da rotina diária; momentos de lazer etc). Em contrapartida, a família homoparental convive com conflitos e discriminação, nos mais variados contextos, que são produtos do preconceito acerca da homossexualidade, compreendida como característica-chave pelos casais.

Ao considerar o exposto, a indagação que sustenta esta tese pode ser assim enunciada: Como vivem e se relacionam, tanto no âmbito privado como público, as famílias constituídas por casais do mesmo sexo/gênero e seus/suas filhos(as)? 
Pesquisas com famílias formadas por casais do mesmo sexo/gênero e seus/suas filhos(as) são meritórias no sentido de expor e discutir um fenômeno recente e ainda pouco estudado no Brasil. Dentre as muitas problematizações que se colocam para defender ou discriminar a legitimidade dessas famílias, encontra-se a questão do preconceito e da estigmatização social, ainda vigente, em relação à homossexualidade.

Nas palavras de Moscheta (2004, p. 6), “a relação homossexual é produzida em contínuo diálogo com as instâncias sociais que, muitas vezes, por preconceito e discriminação, limitam e isolam a experiência conjugal, constituindo uma fonte de angústia”. Se as famílias homoparentais "ganharam visibilidade social nos últimos anos, também foram alvos de ataques e tiveram sua legitimidade e cidadania contestadas por instituições centrais para a vida cotidiana, tais como a Igreja, o poder legislativo e judiciário" (Toledo, 2008, p. 9). Essa resistência relaciona-se com expressões de homofobia que, para Borrillo (2009), significa "atitude de hostilidade para com os homossexuais" (p. 15) manifestadas por meio de julgamentos discriminatórios, agressões verbais ou físicas, violência simbólica, enfim, expressões preconceituosas que atravessam o cotidiano de uma sociedade heteronormativa ${ }^{5}$ e que definem as pessoas homossexuais como "desviantes" em vários espaços sociais, incluindo as constituições familiares.

Em 2011, pela primeira vez, o Governo Federal brasileiro realizou uma pesquisa sistemática acerca dos dados sobre violência homofóbica no país (Secretaria de Direitos Humanos, 2012), que apontaram o registro de 310 casos de homicídios na população LGBT. No ano seguinte, em 2012, o relatório revelou que esse número cresceu $11,51 \%$, alcançando 329 casos (Secretaria de Direitos Humanos, 2013). As estatísticas disponíveis, já alarmantes, provavelmente subestimam a magnitude do problema em função de sua subnotificação e dificuldades de caracterização dos casos de violência por motivação homofóbica.

Recentemente, em junho de 2019, o Supremo Tribunal Federal (STF) enquadrou a homofobia e a transfobia como crimes de racismo ao reconhecer omissão legislativa. Os ministros citaram sobretudo a violência de que gays, lésbicas e transgêneros são vítimas no país:

o Plenário aprovou a tese proposta pelo relator da ADO, ministro Celso de Mello, formulada em três pontos. O primeiro prevê que, até que o Congresso Nacional edite lei específica, as condutas homofóbicas e transfóbicas, reais ou supostas, se enquadram nos crimes previstos na

\footnotetext{
${ }^{5}$ Heteronormatividade: "crença na heterossexualidade como característica do ser humano 'normal'. Desse modo, qualquer pessoa que saia desse padrão é considerada fora da norma, o que justificaria sua marginalização" (Jesus, 2012, p. 29).
} 
Lei 7.716/2018 e, no caso de homicídio doloso, constitui circunstância que o qualifica, por configurar motivo torpe. No segundo ponto, a tese prevê que a repressão penal à prática da homotransfobia não alcança nem restringe o exercício da liberdade religiosa, desde que tais manifestações não configurem discurso de ódio. Finalmente, a tese estabelece que o conceito de racismo ultrapassa aspectos estritamente biológicos ou fenotípicos e alcança a negação da dignidade e da humanidade de grupos vulneráveis. (Supremo Tribunal Federal, 2019). 


\section{JUSTIFICATIVA E OBJETIVOS}

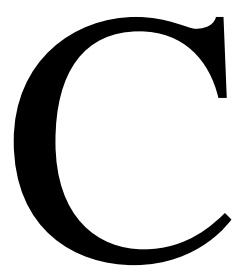

onsiderando a trajetória sociocultural e política da constituição da instituição familiar no decorrer dos tempos, assiste-se, na contemporaneidade, à emergência de inúmeras configurações que se distanciam do tradicional modelo de família. Uma delas é o arranjo caracterizado por casais do mesmo sexo/gênero e seus/suas filhos(as) (Golombok, 2015; Grossi et al., 2007). A temática é relevante no cenário atual, permeado por muitas vozes que insistem em afirmar um tipo apenas de família como sendo a única, verdadeira e legítima, tratando os demais arranjos familiares como periféricos ou ilegítimos. Quando o convívio social é regulado pelo princípio democrático da igualdade dos cidadãos perante a lei, convém afirmar a diversidade de famílias presente em nossa sociedade, o que nos invoca a utilizar o substantivo sempre no plural. Assim, é reconhecida a necessidade de mais estudos que deem visibilidade a essas famílias no contexto nacional, pois é de fundamental importância compreender suas vivências nos âmbitos privado e social (Costa, Pereira, \& Leal, 2012; Goldberg \& Gartrell, 2014).

A discussão sobre essa temática contribui para a ampliação do conceito de família e a diversificação dos estudos sobre as relações entre pessoas do mesmo sexo/gênero. Se há alguns anos a conjugação família-homossexualidade era impensável, bastante difícil ou, ainda, feita às escondidas, ou com inúmeras ressalvas, hoje é uma realidade que ilumina várias possibilidades, empiricamente registradas no espectro social, que necessitam ser incorporadas ao campo da pesquisa em Psicologia.

Estudos em diversos contextos têm evidenciado que as famílias compostas por casais do mesmo sexo/gênero apresentam características e funções comuns a qualquer tipo de configuração familiar, tais como: cuidado, responsabilidades e dificuldades na criação dos(as) filhos(as); planejamento financeiro e da rotina diária; momentos de lazer, entre outros (Almeida, 2012; Goldberg \& Gartrell, 2014; Golombok, 2015; Golombok et al., 2014; Martinez \& Barbieri, 2011; Uziel, 2007). Além disso, pesquisas realizadas no cenário brasileiro demonstram que essa modalidade de família convive com dificuldades e discriminação nos mais variados contextos sociais, diferentemente das famílias constituídas por pessoas cisgêneras e heterossexuais (Corrêa, 2012; Farias \& Maia, 2009; Lira, Morais, \& Boris, 2016; Toledo, 2008; Tombolato et al., 2018).

As motivações para a escolha do tema deste estudo emergem, assim, da confluência entre o desejo e a necessidade de investigar, de maneira sistemática, a vivência de casais homossexuais e de seus/suas filhos(as). Dessa maneira, no decorrer do desenvolvimento da pesquisa, buscou-se lançar luz para os aspectos que permitiram uma compreensão de questões pertinentes ao tema respaldando-se nas vivências daqueles que protagonizam o cenário destas famílias divergentes do 
modelo heteronormativo. Para tanto, intencionou-se dar voz aos protagonistas, para que eles contem a partir de si próprios, as experiências vivas das homoparentalidades.

Ademais, como ficou evidenciado, a produção científica nessa temática ainda é incipiente, com poucas referências no âmbito nacional para orientar programas de prevenção e/ou intervenção, o que dificulta o planejamento de políticas públicas nesse campo. Considera-se que esses estudos sejam necessários também para subsidiar a formação acadêmica em Psicologia, de profissionais de saúde, Educação, Direito e outras áreas relacionadas.

Tais formações acadêmicas e profissionais pouco discutem essa temática, uma vez que as grades curriculares não têm dado a devida relevância a esses assuntos. Espera-se que este estudo, e outras pesquisas relacionadas ao tema, possam gerar conhecimentos que aprofundem os resultados das investigações já realizadas e subsídios para ideações, políticas e estratégias que promovam cidadania e respeito à diversidade. Além de ser imprescindível incentivar medidas preventivas de apoio a essas pessoas e suas famílias na precaução contra atos de violência. Um limitado número de estudos, por exemplo, tem avançado na temática do preconceito e da discriminação voltados às famílias homoparentais brasileiras; logo é inadiável dar visibilidade a esse fato. A divulgação de pesquisas científicas nessa área, a partir das prerrogativas de uma sociedade plural e respeitosa em relação às diferenças, deve contribuir para novas reflexões que transformem posturas preconceituosas e excludentes frente ao desenvolvimento e à multiplicidade dos arranjos familiares nos dias de hoje. 
Diante do exposto com base na revisão da literatura e tendo em vista a indagação que este estudo se propõe a estudar, os objetivos foram conhecer e analisar as vivências ${ }^{6}$ familiares a partir das vozes ${ }^{7}$ de casais do mesmo sexo/gênero e seus/suas respectivos(as) filhos(as). E os objetivos específicos foram conhecer e analisar:

- as trajetórias afetivo-sexuais de casais em relacionamentos homoafetivos que coabitam e têm filhos(as);

- a transição e a vivência da conjugalidade nesses casais;

- a transição-exercício da parentalidade em famílias constituídas por pais/mães do mesmo sexo/gênero;

- os significados atribuídos por pais/mães e filhos(as) à experiência de pertencer a uma família;

- como pais, mães e seus/suas filhos(as) lidam com a questão da visibilidade/invisibilidade do arranjo familiar homoparental no contexto das interações sociais.

${ }^{6}$ Considera-se vivência (Erlebnis, originalmente em alemão) de acordo com esses aspectos: "a percepção que o ser humano tem de suas próprias experiências, atribuindo-lhes significados [...,] acompanhadas de algum sentimento de agrado ou desagrado" (Forghieri, 1993, p. 19). Dessa maneira, "o que é vivenciado deve ter uma intensidade de tal modo significativa, cujo resultado confere uma importância que transforma por completo o contexto geral da existência" (Viesenteiner, 2013, p. 142).

${ }^{7}$ Vozes são consideradas a linguagem onde a expressão da vivência aparece. 


\section{TRAJETÓRIA TEÓRICO-METODOLÓGICA}

\section{CONTEXTUALIZAÇÃO SOBRE A METODOLOGIA QUALITATIVA}

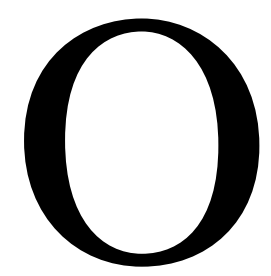

ato de pesquisar compreende um conjunto de atividades dedicadas a produzir novos conhecimentos e, nessa medida, insere-se no contexto das descobertas, abrangendo todas as áreas de conhecimento. Considerada em sua etimologia, a palavra pesquisa provém do latim perquirere - "indagar", “perguntar", a partir da junção de per - “completamente" e quaerere, "perguntar". Desse modo, tem como significado a ação ou o efeito de buscar ou procurar (Kauark, Manhães, \& Medeiros, 2010). O pesquisar, como atividade central do desenvolvimento do campo científico em ciências humanas, tem como objetivos a resolução de um problema, e/ou a descrição de uma realidade/fenômeno, e/ou a compreensão de um determinado contexto, e/ou ainda a predição de comportamentos e a determinação de causas (Cozby, 2003; Creswell, 2008; J. J. S. Fonseca, 2002; Lindlof \& Taylor, 2002; Minayo \& Sanches, 1993; Pernecky, 2016; Savin-Baden \& Major, 2013).

As pesquisas científicas são classificadas de variadas formas, a depender de sua natureza, área, abordagem, e do paradigma, propósito e dos procedimentos metodológicos utilizados para alcançar os objetivos propostos (Pernecky, 2016; Savin-Baden \& Major, 2013). O método descreve o caminho trilhado na pesquisa. Pode ser definido como um conjunto de "procedimentos que consideramos adequados para responder à nossa questão; não é um a priori da pesquisa, ele faz parte dela" (Furlan, 2008, p. 25).

Nessa direção, Minayo (2010) acrescenta que, por metodologia, deve-se entender "o caminho do pensamento e a prática exercida na abordagem da realidade" (p. 16). Assim, "a metodologia inclui simultaneamente a teoria da abordagem (o método), os instrumentos de operacionalização do conhecimento (as técnicas) e a criatividade do pesquisador (sua experiência, sua capacidade pessoal e sua sensibilidade)" (Minayo, 2010, p. 14). O pesquisador está organicamente implicado em todo o processo de produção do conhecimento. A relação estreita entre o pesquisador e seu campo de estudo é uma característica intrínseca à investigação social. Desse modo, parte-se do pressuposto de que a visão de mundo de quem investiga e a do sujeito da pesquisa estão implicadas não apenas no produto final da investigação, mas desde o princípio da concepção do objeto até os resultados obtidos e sua potencial aplicação. Logo, é essencial que o pesquisador conheça a complexidade dos tipos de 
estudos, os diversos delineamentos de pesquisa, para então definir quais os instrumentos e procedimentos que melhor se adequarão aos propósitos de sua investigação (Kauark et al., 2010).

Em uma aproximação inicial, as atividades no campo científico podem ser classificadas em dois grandes eixos: Pesquisas Teóricas e Pesquisas Empíricas. Basicamente, as Pesquisas Teóricas têm como objetivo a construção, revisão e reconstrução de teorias, conceitos e ideologias. Já as Pesquisas Empíricas se caracterizam pela coleta de dados a partir de fontes diretas - pessoas que conhecem, vivenciaram ou têm conhecimento sobre o tema e/ou situação investigada (J. J. S. Fonseca, 2002). As Pesquisas Empíricas são classificadas como quantitativas ou qualitativas. De modo geral, a pesquisa quantitativa usa os princípios da confiabilidade para descrever e avaliar o rigor científico do estudo, enquanto que, na abordagem qualitativa, o rigor está relacionado ao intuito de buscar compreender o conhecimento a partir da concepção particular da realidade dos(as) participantes (Wu, Thompson, Aroian, McQuaid, \& Deatrick, 2016).

A investigação qualitativa pode ser entendida como uma abordagem metodológica ampla que engloba diversos métodos de pesquisa. Os objetivos pretendidos variam muito nas diferentes áreas do conhecimento. A abordagem qualitativa é utilizada em diferentes campos disciplinares, porém é mais disseminada nas ciências humanas e sociais. Isso apropria o fato de que os métodos qualitativos compõem uma paisagem heterogênea e extremamente diversificada (Creswell, 2008; Pernecky, 2016). Desse modo, há múltiplas e distintas metodologias qualitativas, sendo cada uma ancorada em diferentes pressupostos ontológicos e epistemológicos, tais como: abordagem narrativa, sócio histórica, fenomenologia, etnografia, estudo de caso, teoria fundamentada nos dados, teoria crítica, construtivismo, póspositivismo, entre outros enfoques - que se baseiam estreitamente no campo das ciências humanas e sociais.

No campo da Psicologia, quando o investigador intenciona obter uma compreensão em profundidade de determinado comportamento e escrutinar as variáveis que o regulam, ele pode ou não lançar mão de métodos qualitativos. Esses métodos possibilitam examinar como e por quê foi tomada determinada decisão, não apenas o quê, onde, quando ou quem emitiu aquela conduta. Nessa perspectiva, os métodos qualitativos produzem informações minuciosas sobre os casos particulares investigados, sem a finalidade de generalizações (Creswell, 2008; Denzin \& Lincoln, 2005).

De fato, quaisquer conclusões mais gerais devem ser vistas com cautela e consideradas como proposições ou pressupostos informados, não como hipóteses. A relevância da pesquisa 
qualitativa está justamente na sua capacidade de examinar a fundo determinado campo de investigação. Já os métodos quantitativos, contrastando com os qualitativos, podem ser utilizados para buscar apoio empírico para tais pressupostos de pesquisa (Lindlof \& Taylor, 2002).

O investigador qualitativo frequentemente não tem constituída a total compreensão prévia acerca do fenômeno pesquisado (Denzin \& Lincoln, 2005). Pode partir de um préreflexivo, como na investigação de inspiração fenomenológica, ou pode lançar mão de uma abordagem teoricamente fundamentada, como a grounded theory. Pode aplicar os princípios balizadores do estudo de caso, com a finalidade de examinar em profundidade amostras de conveniência (ou intencionais) para explorar um determinado fenômeno (Stake, 1995).

De acordo com Bogdan e Taylor (1990), o pesquisador pode iniciar seu estudo com proposições gerais acerca da realidade a ser investigada e proceder de forma científica e empírica ao longo do processo de investigação. A compreensão abrangente de um fenômeno, evento ou situação deriva da exploração da totalidade da situação. Por isso, o recorte a ser feito no estudo necessariamente tem de ser bem delimitado, ainda que esse procedimento possa permitir o acesso a uma quantidade considerável de dados, que precisam ser ordenados.

$\mathrm{Na}$ atualidade, a pesquisa qualitativa utiliza um número amplo de paradigmas, que refletem as preocupações conceituais e teóricas dos investigadores contemporâneos (Pernecky, 2016). Questões de identidade, por exemplo, que emergiram a partir da década de 1980 e que podem incluir problemáticas relacionadas à etnia/“raça", classe, gênero, diversidade cultural e comunidades discursivas, levaram a pesquisa no campo das ciências sociais a se tornarem cada vez mais reflexivas e aprofundadas. Os pressupostos teóricos, ontológicos e epistemológicos são, cada vez mais e melhor, contextualizados pelos pesquisadores. O que se valoriza é a busca de legitimidade na comunidade científica, principalmente frente a outros paradigmas mais consolidados historicamente, como os derivados do positivismo e de outras matrizes teórico-epistemológicas. Entende-se que a garantia de rigor na análise dos dados, a reflexividade em todas as etapas da pesquisa e a descrição densa e minuciosa dos procedimentos utilizados são, em última instância, os aspectos que garantem a legitimidade do método empregado. A tendência que se observa entre os pesquisadores qualitativistas é a opção por paradigmas mais interpretativos, críticos e com abordagens participativas.

As metodologias qualitativas podem ser compreendidas como uma família de abordagens que compartilham de certas características que são comuns e que as distinguem da pesquisa quantitativa (Wu et al., 2016). Nessa perspectiva, pode-se afirmar que "a pesquisa 
qualitativa se ocupa com o universo dos significados, dos motivos, das aspirações, das crenças, dos valores e das atitudes" (Minayo, 2010, p. 21).

$\mathrm{Na}$ paisagem heterogênea das abordagens qualitativas contemporâneas, o termo "pesquisa interpretativa" tem sido utilizado para nomear os estudos de delineamento qualitativo e as pesquisas indutivas (Lowenberg, 1993). A visão compreensivo-interpretativa, conforme pontuado por Minayo (2010), decorre do reconhecimento básico de que no ato de pesquisar estão envolvidos os processos interpretativos e cognitivos inerentes à vida social. Esses processos são fortemente enfatizados nessas abordagens.

Ademais, a investigação qualitativa possui determinadas características que são substanciais ao cenário a ser estudado, podendo-se destacar: a preocupação com o contexto no qual os sujeitos estão inseridos; a valorização da descrição dos dados obtidos - analisando-os em toda a sua profundidade e riqueza; o interesse do pesquisador pelo processo em vez de focar simplesmente nos resultados; e a relevância do significado que cada participante atribui às experiências vividas. Nessa vertente, Guba e Lincoln (2005) identificam cinco paradigmas principais da pesquisa qualitativa contemporânea: positivismo, pós-positivismo, teorias críticas, construtivismo e paradigmas participativos-cooperativos. Essas vertentes refletem diferenças axiomáticas, objetivos propostos, controle de processos e desfechos de pesquisa, relação com fundamentos de verdade e conhecimento, representação textual, validade e voz do pesquisador e dos participantes. Desse modo, a pesquisa qualitativa visa a ampliar o conhecimento sobre o fenômeno em questão por meio da análise realizada a partir do levantamento de informações originárias dos relatos dos(as) próprios(as) participantes (Lüdke \& André, 1986).

Com isso, tendo em vista a natureza da indagação levantada neste estudo: "como vivem e se relacionam, tanto no âmbito privado como público, as famílias constituídas por casais do mesmo sexo/gênero e seus/suas filho(as)?", e delineada pelo objetivo principal: "conhecer as vivências familiares a partir das vozes de casais do mesmo sexo/gênero e seus/suas respectivos(as) filhos(as)", optou-se por efetuar uma investigação qualitativa, entendendo que essa abordagem possibilita uma visão compreensivo-interpretativa do fenômeno estudado pelo vértice do vínculo direto e intersubjetivo estabelecido entre o pesquisador e os(as) participantes (Lüdke \& André, 1986).

No panorama qualitativo de pesquisa, nota-se a existência de variados tipos de pesquisa fenomenológica. Amatuzzi (1996) evidencia seis deles: (1) pesquisa fenomenológica como filosofia, que visa a esclarecer o conhecimento a partir da descrição daquilo que se mostra, abstendo-se de juízos a priori e sem concepções explicativas; (2) fenomenologia eidética, que elucida vivências por meio da reflexão e redução fenomenológica, (3) 
fenomenologia hermenêutica, na qual a compreensão do vivido se dá pela interpretação do pesquisador, (4) psicologia fenomenológica “empírica”, que aplica a filosofia fenomenológica aos estudos em psicologia com dados empíricos, (5) pesquisa psicológica "experimental”, que combina a fenomenologia empírica com a intervenção do método experimental, e (6) pesquisa colaborativa, na qual a pesquisa fenomenológica é aplicada aos fenômenos do processo grupal. No presente estudo focalizamos, apresentamos e analisamos reflexivamente a abordagem teórico-metodológica da Análise Fenomenológica Interpretativa - AFI, uma proposta recente de sistematização da investigação científica em pesquisa qualitativa, que se insere também no paradigma fenomenológico. Em consequência disso, ao mesmo tempo, é válido ressaltar que a abordagem adotada se trata apenas de um entre os múltiplos olhares possíveis no estudo, neste caso, sobre os arranjos familiares.

Com a finalidade de aprimorar o rigor metodológico, esta tese adotou as orientações do COREQ (Consolidated Criteria for Reporting Qualitative Research), que foram construídas após as pesquisas desenvolvidas por Tong, Sainsbury e Craig (2007). O COREQ abarca uma lista de 32 itens, em língua inglesa, que é utilizada para orientar a preparação de relatórios e/ou a apresentação de pesquisas qualitativas que utilizaram entrevistas ou grupos focais na área da saúde. Tem o objetivo de garantir o maior detalhamento e a possível reprodução dos passos metodológicos da pesquisa, possibilitando a compreensão do modo como ela foi delineada e conduzida, assim como a maneira a qual os dados foram acessados, analisados e interpretados. Para cada um dos 32 itens, o pesquisador deve citar o respectivo número da página de seu estudo. Com isso, todos os itens devem ser contemplados. Esses 32 itens estão organizados em três grandes domínios: (1) equipe de pesquisa e reflexividade, (2) desenho do estudo, e (3) análise de dados e relatório. Alguns desses itens são: qual autor conduziu as entrevistas? Como os(as) participantes foram selecionados(as)? Os(As) participantes forneceram feedback sobre os resultados?

A lista (COREQ) preenchida, pertinente a este estudo, está disponível no APÊNDICE A. 


\section{ANÁLISE FENOMENOLÓGICA INTERPRETATIVA - AFI}

A Análise Fenomenológica Interpretativa - AFI (acrônimo em português para Interpretative Phenomenological Analysis - IPA) é a fundamentação teórica e metodológica que inspirou esta tese. O conteúdo apresentado em destaque nesta seção refere-se aos princípios teóricos da abordagem, e que são baseados, principalmente, no livro: "Interpretative Phenomenological Analysis: theory, method and research" de autoria de Jonathan A. Smith, Paul Flowers e Michael Larkin, psicólogos e professores de universidades britânicas, respectivamente Birkbeck University of London, Glasgow Caledonian University e University of Birmingham (Smith, Flowers, \& Larkin, 2009). Essa obra foi publicada no ano de 2009 em língua inglesa, e ainda não se encontra traduzida para a língua portuguesa. Tratase de uma referência primordial, que oferece um painel amplo e detalhado que serve como guia sobre os aspectos teóricos, metodológicos e aplicados da AFI, e que está integralizada no decorrer deste estudo.

\section{AS PÁGINAS SEGUINTES NÃO FORAM}

